\title{
Impact of surface sizing on inkjet printing quality
}

\author{
Isabel M. T. Moutinho*, Paulo J. T. Ferreira, Margarida L. Figueiredo
}

Chemical Engineering Department - Coimbra University, Polo II - Rua Silvio Lima, 3030-790

Coimbra, Portugal, E-mail: isamim@gmail.com, Phone +351.239.798.700, Fax +351.239.798.703.

\begin{abstract}
Printing quality is strongly influenced by the structural and chemical properties of paper surface, and is one of the most important factors concerning costumer's evaluation. Thus, all studies regarding the evaluation of paper surface characteristics, the effects of surface treatments, paper-ink interactions as well as the influence of all these parameters on printing quality, are of utmost importance.
\end{abstract}

The aim of this study is to analyze the influence on printing quality of different chemical surface treatments used in printing and writing papers and also identify the most relevant parameters for inkjet printing quality evaluation. For that, four paper samples were studied.

Differences in the performance of the distinct samples were detected, and interpreted in terms of the different treatments. The results also revealed that contact angles measurements are a valuable tool to predict paper's inkjet printing behavior. 


\section{KEYWORDS}

Paper, surface sizing, inkjet printing, printing quality

\section{INTRODUCTION}

At present, there is an increasing demand concerning the quality of printing and writing paper grades $(\mathrm{P} \& \mathrm{~W})$. The performance of this commodity depends on the properties of the fibrous matrix and on the characteristics of the paper surface, which are influenced by the quality of the pulp fibers, the refining process, the chemicals added in the preparation of the furnish, the operations at the paper machine and the modifications of the paper surface ${ }^{1-4}$. These modifications include calendering and/or chemical treatments such as coating and surface sizing ${ }^{1 ; 3 ; 5 ; 6}$. Today, chemical modifications of paper surface for improving printing quality is a common practice in papermaking and, as a consequence, there is a large increase in the production of new chemicals that meet specific end-use paper requirements.

For surface sizing, cationic starch alone or a mixture of cationic starch and a synthetic polymer are used to control the hydrophilic character of paper surface, preventing excessive absorption of liquids and inks ${ }^{1 ; 3}$. As depicted in Figure 1, a thin reticular matrix film is formed at paper surface. This film reduces the number and size of pores as well as paper roughness, and modifies paper surface energy, so that not only liquid penetration but also liquid spreading is attenuated ${ }^{1 ; 3 ; 5}$. Surface sizing is affected by the sizing formulation properties (composition, viscosity, $\mathrm{pH}$, temperature) as well as the paper properties (basis weight, bulk, internal sizing, water content and surface energy, porosity and roughness) $4 ; 6 ; 7$. However, these properties must be adequately controlled in order to avoid too much penetration of the surface sizing agent in the sheet structure. 

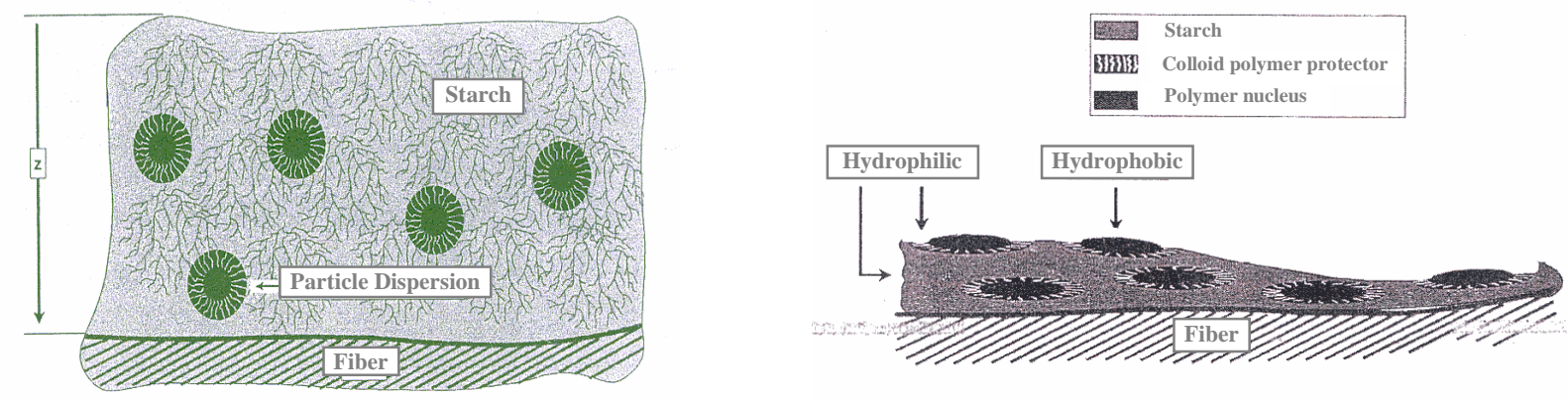

Figure 1. Polymer-starch film formation on paper surface ${ }^{3}$.

For selecting the most appropriate surface sizing agent for a specific paper it is essential to test its performance at lab scale. On one hand, parameters of the surface sized paper, like energy, porosity and roughness, which largely influence ink spreading, penetration and drying, have to be determined. On the other hand, it is crucial to evaluate the effect of surface sizing on printing quality. With this regard, and although the customer perception is still important, it is necessary to use more objective procedures to access printing quality. In this context, optical density, raggedness, sharpness, mottling, bleeding, line and dot quality and Gamut area are some of the relevant properties that should be taken into account when printing processes that involve low viscosity fluids are used, as ink-jet printing, whose inks are usually water based $1 ; 5 ; 7 ; 8$.

Many studies can be found in the open literature concerning paper coating and the characterization of paper surface, both in physical and chemical terms ${ }^{8-11}$. However, not many studies have been performed and published regarding surface sizing of fine papers and the information related to the parameters that should be measured in order to evaluate inkjet printing quality is scarce.

This study is part of a comprehensive work aiming at understanding the mechanisms that rule surface sizing of $\mathrm{P} \& \mathrm{~W}$ paper grades, its interactions with paper surface and its influence on the end-use paper properties. Specifically, the objective of this study is to evaluate the influence of different surface sizing treatments on printing properties and to validate a restricted set of parameters for an adequate 
assessment of printing quality. It should be mentioned that this is a pioneer work as far as surface sizing of eucalyptus pulps based papers is concerned. Besides, the use of synthetic polymers for surface sizing in industry is still very limited and there is no general agreement on which printing parameters should be considered for inkjet printing quality evaluation.

\section{EXPERIMENTAL METHODS}

A calendered commercial uncoated base paper $\left(80 \mathrm{~g} / \mathrm{m}^{2}\right)$ produced with a Eucalyptus globulus kraft pulp without any surface treatment (S0) was surface sized with cationic starch (S1), with a blend of cationic starch and co-styrene-maleic anhydride (S2) and with another blend of cationic starch and costyrene-acrylate (S3), as described in Table I. These surface sized samples were no further calendered.

Table 1. Sample description.

\begin{tabular}{cc}
\hline Sample & Surface sizing formulation $(\% \mathbf{w} / \mathbf{w})$ \\
\hline S0 & No Surface Treatment \\
\hline S1 & $100 \%$ Cationic Starch \\
\hline S2 & $\begin{array}{c}80 \% \text { of cationic starch } \\
\text { 20\% of co-stryrene-maleic anhydride }\end{array}$ \\
\hline S3 & $\begin{array}{c}80 \% \text { of cationic starch } \\
\text { 20 }\end{array}$ \\
& $20 \%$ of co-styrene-acrylate \\
\hline
\end{tabular}

The surface sizing formulations were applied using a Mathis laboratory coating device, SVA-IR-B, which operates automatically with different velocities of the applicator roll (Figure 2). A $0.15 \mathrm{~mm}$ roll was used and its velocity was adjusted to $6 \mathrm{~m} / \mathrm{min}$.

The drying process was performed in two steps: using an IR drier coupled to the applicator roll (1.0 $\mathrm{kW}$ drying intensity) followed by air drying for at least $10 \mathrm{~min}$. The total surface sizing pick-up was 3.5 $\pm 0.3 \mathrm{~g} / \mathrm{m}^{2}$. 


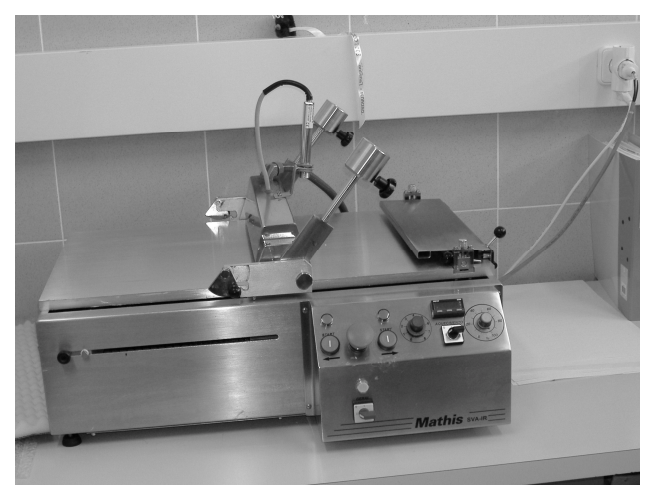

Figure 2. Coating equipment used in the production of the surface sized samples.

A schematic representation of the copolymers used in this work, computed using the software ChemSketch, is presented in Figure $3^{12}$.

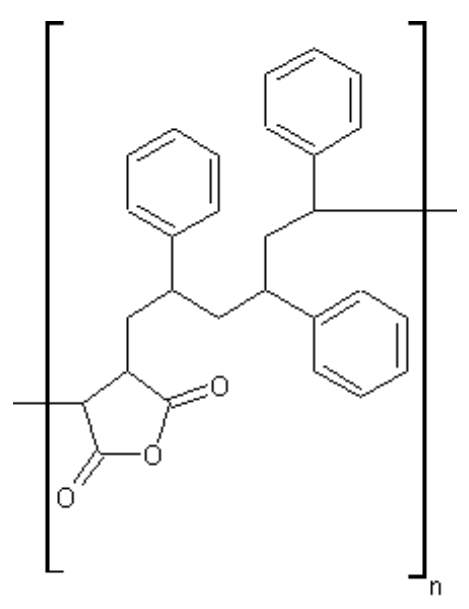

(a)

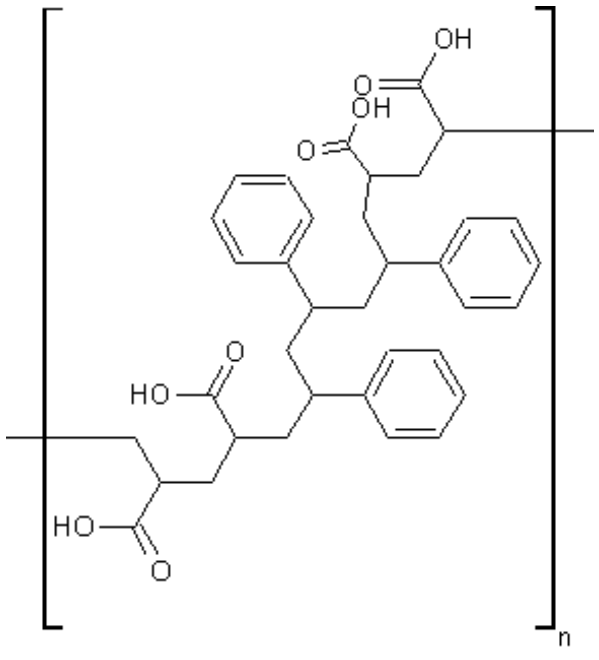

(b)

Figure 3. Schematic representation of the surface sizing; (a) co-styrene-maleic anhydride ; (b) costyrene-acrylate.

The Styrene copolymers were selected due to their different hydrophobic character (Maleic anhydride is more hydrophobic than Acrylate). Some properties of the compounds used in this work were 
determined in laboratory and the results are presented in Table II. The monomers proportion of each copolymer was calculated based on elemental analysis measurements.

Table 2. Properties of the compounds used to produce the surface sizing formulations.

\begin{tabular}{|c|c|c|c|c|c|c|}
\hline Compound & $\begin{array}{l}\text { Monomers } \\
\text { Proportion }\end{array}$ & $\begin{array}{c}\text { Solids } \\
\text { Content } \\
(\%)\end{array}$ & pH & $\begin{array}{c}\text { Molecular } \\
\text { weight } \\
\text { (g/mol) }\end{array}$ & $\begin{array}{c}\text { Molar } \\
\text { Volume } \\
\left(\mathrm{cm}^{3}\right)\end{array}$ & $\begin{array}{c}\text { Surface } \\
\text { Tension } \\
\text { (dine/cm) }\end{array}$ \\
\hline Cationic starch $^{*}$ & n.a. & 12.8 & 6.7 & 160.1 & 107.0 & 66.8 \\
\hline Co-styrene-maleic anhydride & $3: 1$ & 14.9 & 8.4 & 410.5 & 359.9 & 47.9 \\
\hline Co-styrene-acrylate & $3: 4$ & 25.2 & 5.0 & 600.7 & 489.6 & 56.0 \\
\hline
\end{tabular}

For evaluating the impact of surface sizing on paper surface properties and inkjet printability, contact angle measurements were performed with the DataPhysics equipment OCA20, using the sessile drop method ${ }^{13}$. However, and since the results of the contact angle measurements depend upon the samples surface topography, namely paper roughness, preliminary 3D topographical measurements were carried out for the four samples, using the AltiMet perfilometer Altisurf 500 coupled with the PaperMap software. For each sample, specimens of $4 \times 4 \mathrm{~mm}^{2}$ were scanned. From the 2000 profiles obtained for each specimen the following parameters were computed: average roughness (Sa, $\mu \mathrm{m})$, defined as the arithmetic average of the absolute values of the surface height deviations measured from the best fitting plane; maximum peak height $(\mathrm{Sp}, \mu \mathrm{m})$ and maximum valley depth $(\mathrm{Sv}, \mu \mathrm{m})$, both measured relatively to the mean plane; and the interfacial area ratio $(\mathrm{Sdr}, \%)$, which indicates the complexity of the curvelinear surface compared to the support surface ${ }^{14}$. In this study, the influence of topography on the contact angle measurements was accounted for by using the Wenzel correction ${ }^{15-18}$ :

$$
\cos (\theta)=R \cdot \cos \left(\theta^{\prime}\right)
$$

where $\theta$ is the measured contact angle, $\theta^{\prime}$ is the corrected contact angle and $\mathrm{R}$ is the topographical correction factor given by: 


$$
R=1+\frac{S d r}{100}
$$

(Equation 2)

In order to analyze the interaction between paper surface and inkjet ink, static and dynamic contact angles with black inkjet ink (drops of $7 \mu \mathrm{l}$ ) were measured. Additionally, and since inkjet inks are water based (the usual inkjet inks composition is $65 \%$ water, $30 \%$ humectant, $2-5 \%$ dye or pigment and $2-5$ $\%$ surfactants and additives $\left.{ }^{19}\right)$, both static and dynamic contact angles using water drops $(10 \mu \mathrm{l})$ were also measured. In fact, dynamic contact angles give relevant information on the way liquids spread and/or absorbed at the paper surface, whereas the static contact angle measurements is used to assess the initial paper wetting. In the latter, the resting drop image immediately after application of the liquid $(<3 \mathrm{~s})$ was captured using a CCD camera and the corresponding contact angle was computed using the Laplace-Young method ${ }^{20 ; 21}$. For each sample, an average of 10 measurements was considered. As for the evolution of the contact angle with time, successive images of the ink or water drops were captured during five minutes and the corresponding contact angle, drop volume and drop base diameter were calculated using the Ellipse fitting method ${ }^{20}$. At least three measurements were carried out for each sample and one of them was randomly selected for further analysis. The wetting velocity was then derived from the contact angle values after 5 and 60 seconds ( $\theta_{5}$ and $\theta_{60}$ respectively), according to the Tappi standard T458 om- $89^{22}$ :

$$
\text { Wetting velocity }\left({ }^{\circ} / \mathrm{sec}\right)=\frac{\theta_{5}-\theta_{60}}{55}
$$

The absorption and spreading coefficients were computed by using the drop volume and base diameter, respectively, at several time intervals, according to following equations:

$$
\begin{aligned}
& \text { Absorption Coeficient }=\frac{V_{i}-V_{f}}{V_{i}} \\
& \text { Spreading Coeficient }=\frac{d_{f}-d_{i}}{d_{i}}
\end{aligned}
$$


where $V$ and $d$ are the drop volume and the drop base diameter, respectively, and the subscripts $i$ and $f$ stand for the initial and final values (after a given time interval).

Additionally to the measurement of the static water contact angle, other liquid probes with known surface tension were tested for each sample, in order to derive the total solid surface energy and its dispersive and polar components, valuable parameters to better understand paper-ink interactions. The OWRK method was applied in these calculations. The theory behind this method and the surface tension values of the liquid probes used are detailed elsewhere ${ }^{23}$.

To complement these results, inkjet printing quality was evaluated by measuring optical density, gamut area and some line and dot quality parameters in a specified mask printed on the paper samples. These properties were chosen because the optical density and gamut area are well correlated with the end users perception, whereas the line and dot quality parameters are commonly used in many paper mills for evaluating printing quality.

As expressed in Equation 4, optical density (D) is given by the relation between the intensity of the light reflected from a paper sheet before and after printing, $\mathrm{I}_{\mathrm{i}}$ and $\mathrm{I}_{\mathrm{f}}$ respectively (a higher value of optical density means less ink penetration) ${ }^{24}$. Optical density measurements were performed using the spectrophotometer Gretag D19C.

$$
D=\log _{10}\left(\frac{I_{i}}{I_{f}}\right)
$$

Gamut area, which corresponds to the range of reproducible colours, is the area of the hexagon whose vertices correspond to the pairs $\left(\mathrm{a}^{*}, \mathrm{~b}^{*}\right)$, where $\mathrm{a}^{*}$ and $\mathrm{b}^{*}$ are the CIE Lab colour coordinates obtained for each colour (cyan, yellow, magenta, green, blue and red) and plotted as depicted in Figure $4{ }^{24 ; 25}$. In this work, the colour coordinates were assessed by using the Datacolor spectrophotometer, Mercury 3000 . 


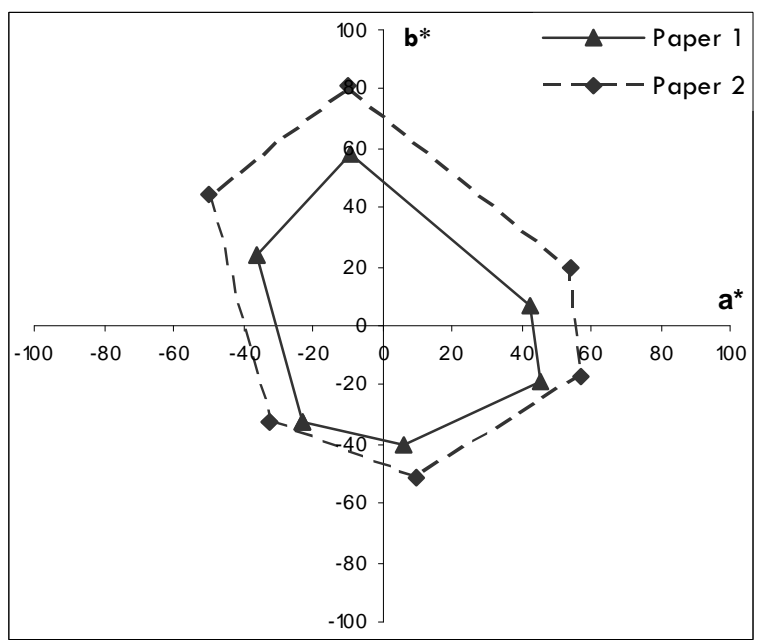

Figure 4. Example of Gamut area's graphic representation (Paper 2 shows a better performance than Paper 1 since larger the gamut area, greater the potential of a paper to reproduce colours).

As for the line quality, line width, raggedness (a measure of the contour irregularity), blurriness (a measure of the sharpness of the outline between the printed and non printed areas) and inter-colour bleed (a measure of the mixture between two adjacent colours) were evaluated. Dot quality was assessed by quantifying dot gain and circularity. All line and dot quality measurements were performed in the QEA portable digital microscope, Personal Image Analysis System (PIAS).

\section{RESULTS AND DISCUSION}

The results of the 3D topographical parameters are presented in Table 3.

Table 3. 3D topographical parameters of the paper samples.

\begin{tabular}{ccccc}
\hline Sample & Sa $(\boldsymbol{\mu m})$ & Sp $(\boldsymbol{\mu m})$ & Sv $(\boldsymbol{\mu m})$ & Sdr $(\boldsymbol{\%})$ \\
\hline S0 & 2.87 & 8.37 & 10.73 & 10.27 \\
\hline S1 & 2.92 & 8.83 & 10.88 & 11.33 \\
\hline S2 & 2.72 & 8.14 & 10.50 & 9.23 \\
\hline S3 & 2.78 & 8.58 & 9.81 & 9.43
\end{tabular}

Sa - average roughness; Sp - maximum peak height; Sv - maximum valley depth; $\mathrm{Sdr}$ - interfacial area ratio. 
From these values it is possible to see that all samples exhibit a similar surface topography, although samples S0 and S1 show slightly higher roughness values, especially with regard to the interfacial area ratio (Sdr). In spite of the small differences on the topographical parameters, the Wenzel correction was applied to the average of the measured contact angle values, and the results are listed in Table 4.

Table 4. Static contact angle values, measured and corrected using Wenzel's correction (Equation (1) and (2)), for water and black ink.

\begin{tabular}{ccccc}
\hline \multirow{2}{*}{ Sample } & \multicolumn{2}{c}{ Measured values $\left({ }^{\mathbf{0}}\right)$} & \multicolumn{2}{c}{ Corrected values $\left({ }^{\mathbf{0}}\right)$} \\
\cline { 2 - 5 } & Water & Black ink & Water & Black ink \\
\hline S0 & $101.9 \pm 2.0$ & $82.5 \pm 3.4$ & 103.1 & 81.7 \\
\hline S1 & $30.4 \pm 2.0$ & $25.9 \pm 0.6$ & 39.2 & 36.1 \\
\hline S2 & $79.6 \pm 2.6$ & $62.7 \pm 1.0$ & 80.5 & 65.2 \\
\hline S3 & $57.0 \pm 1.3$ & $57.4 \pm 1.1$ & 60.2 & 60.5 \\
\hline
\end{tabular}

Comparing the contact angle values before and after correction, no significant differences are noticed for samples S0, S2 and S3, whereas for sample S1 the contact angle increases by approximately $30 \%$, as a consequence of the larger value of Sdr. Thus, it may be concluded that the quite considerable differences between the contact angles of the various samples are most definitely a result of the differences on the surface chemistry and surface size treatment.

From Table 4 it is also evident the extremely large contact angle values $\left(>90^{\circ}\right)$ obtained for the unsized sample (S0), indicating its excessively high hydrophobic character, consequence of the high degree of internal sizing. It should be stressed, however, that this is a factor we can not control since the base paper was industrially produced. Similar results for water contact angle measurements of commercial office papers were obtained also by other authors ${ }^{26}$. All the other samples exhibit contact angles inferior to $90^{\circ}$ for both water and black ink, being those corresponding to the sample surface sized only with cationic starch (sample S1) much smaller than those of samples S2 and S3, which contain copolymers in the sizing formulation. This was to be expected since cationic starch increases 
the hydrophilic character of paper surface, whereas the synthetic sizing agents added to the starch, although representing only $20 \%(\mathrm{w} / \mathrm{w})$ of the sizing formulation of samples S2 and S3, attenuate the starch's hydrophilic effect and lead to a considerable increment of the contact angles. On the other hand, the large values measured for sample S2 are well explained by the fact of the Maleic anhydride based copolymer being less hydrophilic than that of Acrylate.

From the comparison between the values obtained for water and black ink, it can be noticed that the former are in general superior to the latter. This is certainly related to the differences in the liquids surface tension ( 72 dynes/cm to the water and 30-60 dynes/cm to the ink ${ }^{4}$ ).

The evolution of contact angle with time, normalized in relation to the initial contact angle, is plotted in Figures 5 and 6, respectively for water and black ink.

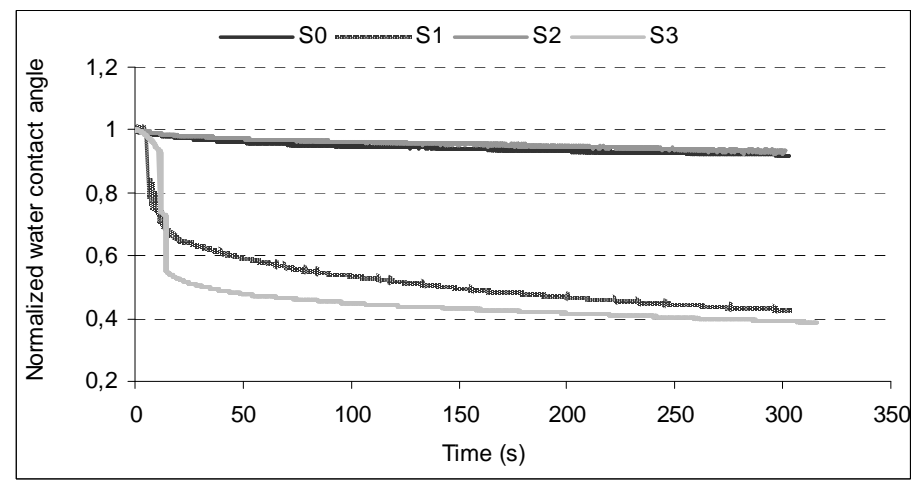

Figure 5. Water dynamic contact angles (normalized values in relation to the initial contact angle).

From Figure 5 it is clear that the samples possessing a higher affinity to water (S1 and S3) present, as expected, an abrupt diminution of the contact angle as a result of spreading and absorption phenomena. Samples S0 and S2 display very close behaviors, exhibiting a much smaller and smoother contact angle decrease throughout time. This is caused by the stronger hydrophobic character of these samples (although, as shown in Table 4, sample S0 possesses a contact angle larger than $90^{\circ}$ thus delaying water wetting ). Although similar trends were observed from the results carried out with the black ink (Figure 6), the profiles exhibit lower slopes, with sample S3 showing a stepwise behavior. This indicates that 
spreading and absorption is less pronounced for black ink drops than for water drops, which is expected considering the lower ink surface tension.

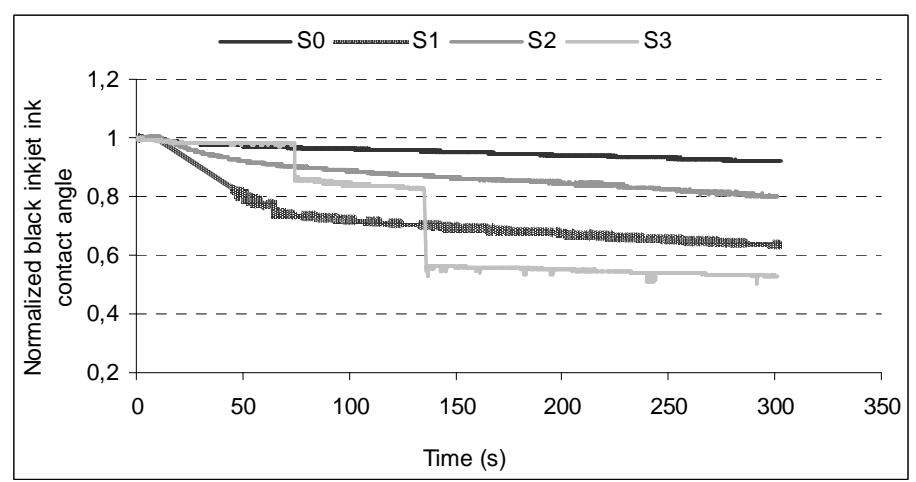

Figure 6. Black inkjet ink dynamic contact angles (normalized values in relation to the initial contact angle).

In order to quantify these phenomena, the values of the absorption and spreading coefficients, derived from Equations 4 and 5, respectively, together with the wetting velocities (Equation 3) are listed in Table 5. Some difficulties were, however, experienced in accurately measuring the drops volume (poor reproducibility due to the wetting of the paper surface) of various samples, and so the corresponding absorption coefficients were not calculated.

Table 5. Absorption and Spreading coefficients (calculated from Equations 4 and 5 after 30 seconds), and Wetting Velocity (Equation 3), for water and black inkjet ink.

\begin{tabular}{ccccccc}
\hline \multirow{2}{*}{ Sample } & \multicolumn{2}{c}{ Absorption (\%) } & \multicolumn{2}{c}{ Spreading (\%) } & \multicolumn{2}{c}{ Wetting Velocity (\%/sec) } \\
\cline { 2 - 7 } & Water & Black ink & Water & Black ink & Water & Black Ink \\
\hline S0 & 0.054 & 0.020 & 0.019 & 0.011 & 0.081 & 0.045 \\
\hline S1 & ---- & 0.076 & 0.287 & 0.012 & 0.245 & 0.086 \\
\hline S2 & ---- & 0.081 & 0.021 & 0.019 & 0.036 & 0.002 \\
\hline S3 & 0.241 & ---- & 0.242 & 0.033 & 0.531 & 0.015 \\
\hline
\end{tabular}

For the cases where both absorption and spreading coefficients are available, it can be noticed that the former are in general larger than the latter, for both water and black ink, confirming the predominance of the absorption phenomenon. Furthermore, the relative behavior of the spreading values as well as of 
the wetting velocities is also as expected (Table 4 and Figures 5 and 6) corresponding the smaller values to samples S0 and S2.

To complement this study, and since the contact angle technique also provides information on the surface free energy and its dispersive and polar components; these parameters were also calculated, being presented in Table 6.

Table 6. Surface free energy and corresponding dispersive and polar components for the different paper samples.

\begin{tabular}{cccc}
\hline \multirow{2}{*}{ Sample } & \multicolumn{3}{c}{ Surface Energy (mN/m) } \\
\cline { 2 - 4 } & Total & Dispersive Component & Polar Component \\
\hline S0 & 39.53 & 39.49 & 0.04 \\
\hline S1 & 51.25 & 35.4 & 15.85 \\
\hline S2 & 38.39 & 37.92 & 0.47 \\
\hline S3 & 42.39 & 38.52 & 3.87 \\
\hline
\end{tabular}

From the analysis of this table, it can be concluded that the best performance of samples S0 and S2 seems to be related to the smaller value of their surface energy, being the difference between them a result of the larger polar component of sample S2. This is certainly caused by the surface sizing applied to this sample which allows adequate initial wetting while keeping a good dynamic behavior. This permits to anticipate a better inkjet printing performance of sample S2.

With regard to the printing quality parameters, the optical density and gamut area results are listed in Tables 7 and 8, respectively.

Table 7. Optical Densities for distinct colours.

\begin{tabular}{ccccc}
\hline Sample & \multicolumn{4}{c}{ Optical Density } \\
\cline { 2 - 5 } & Black & Cyan & Magenta & Yellow \\
\hline S0 & 1.29 & 0.94 & 0.92 & 1.04 \\
\hline S1 & 1.53 & 1.02 & 1.04 & 1.01 \\
\hline S2 & 1.56 & 1.09 & 1.05 & 1.004 \\
\hline S3 & 1.53 & 0.99 & 1.00 & 0.98 \\
\hline
\end{tabular}


The optical density values corresponding to the black ink are, as expected, much higher than those of the other colours (50\% higher). For this parameter, the differences between the paper samples are not so obvious. Nevertheless sample S2 presents, in general, slightly larger values, confirming that ink retention at paper surface is more pronounced, while sample S0 presents, in general, the smaller values, indicating that in despite of the good behavior in the dynamic contact angle measurements, the excessive hydrophobic character tends to be prejudicial for printing as previously mentioned. The better performance of sample S2 is, however, more noticeable if the gamut area is considered (Table 8): the highest value corresponds to sample S2, followed by samples S1, S3 and finally S0.

Table 8 . Gamut Areas for the different samples.

\begin{tabular}{cc}
\hline Sample & Gamut Area \\
\hline S0 & 6523.37 \\
\hline S1 & 7285.07 \\
\hline S2 & 7432.25 \\
\hline S3 & 6916.87 \\
\hline
\end{tabular}

As for line and dot printing quality, which reflect the image definition, the results are presented in Tables 9 and 10.

Table 9. Line printing quality parameters.

\begin{tabular}{ccccc}
\hline \multirow{2}{*}{ Sample } & \multicolumn{4}{c}{ Horizontal Line* $^{*}$} \\
\cline { 2 - 5 } & Width $(\mu \mathbf{m})$ & Raggedness $(\mu \mathbf{m})$ & Blurriness $(\boldsymbol{\mu m})$ & Inter Colour Bleed ${ }^{*}$ \\
\hline S0 & 345.42 & 10.42 & 135.43 & 50.64 \\
\hline S1 & 393.22 & 10.86 & 121.69 & 39.94 \\
\hline S2 & 380.38 & 8.95 & 119.27 & 42.27 \\
\hline S3 & 383.70 & 10.16 & 91.86 & 39.24 \\
\hline
\end{tabular}

* The target for width is $350 \mu \mathrm{m}$, while for raggedness, blurriness and inter colour bleed the lowest value corresponds to the best printing quality.

** Yellow-black bleed 
Table 10. Dot printing quality parameters.

\begin{tabular}{ccc}
\hline \multirow{2}{*}{ Sample } & \multicolumn{2}{c}{ Black Dot } \\
\cline { 2 - 3 } & Gain (\%)* & Circularity** \\
\hline S0 & 420.83 & 2.30 \\
\hline S1 & 453.99 & 2.39 \\
\hline S2 & 420.47 & 2.03 \\
\hline S3 & 424.73 & 1.78 \\
\hline
\end{tabular}

* Gain $=\frac{D_{f}-D_{i}}{D_{i}}$, being $\mathrm{D}_{\mathrm{i}}$ and $\mathrm{D}_{\mathrm{f}}$, respectively the expected (initial) and the obtained (final) values of dot diameter.

** The target for circularity is 1 (perfect circle).

The analysis of these results is more difficult than that of the previous ones. In fact, considering the targets for each parameter, it may be concluded that samples S0 and S1 have the poorest performances, however sample S2 does not present the most favorable values for all parameters. Such is the case of blurriness, inter colour bleed and dot circularity. For these parameters, the best results (smaller values) correspond to the samples with a more hydrophilic surface (S1 or S3), which means that blurriness, inter colour bleed and dot circularity are attenuated when ink absorption is more pronounced. Therefore, it is legitimate to conclude that a certain degree of hydrophilicity contributes to improve the printing definition. These results highlight the risk of analyzing the parameters individually/separately.

\section{CONCLUSIONS}

The contact angle measurement has proved to be a very useful tool to evaluate the influence of the sizing formulation on the printing properties. As a matter of fact, considerable differences were achieved between the values of the contact angles obtained for the various paper samples, even after correction for paper roughness. Moreover, the additional information about surface free energy and the corresponding dispersive and polar components was also found to be most valuable to explain differences in sample behavior. 
As expected, the unsized paper (sample S0) was found to exhibit a poor performance regarding printing properties (despite the apparently favorable variation profile of the contact angle with the time) as a consequence of the extremely high value of the initial contact angle, which delays ink absorption.

In relation to the paper sized only with cationic starch (sample S1), it was observed that the combination of starch and synthetic surface sizing agents resulted in a significant increase in contact angle, depending on the hydrophobic character of the sizing agent: higher values were measured for the samples including co-styrene-maleic anhydride (sample S2) than for those containing co-styreneacrylate (sample S3). The results concerning the contact angle evolution throughout time (dynamic contact angle) also attributed the best performance of the sized papers to sample S2. These findings were validated by the results obtained for optical density and gamut area measured in a printed mask. Being these two parameters very much related to costumer's perception, it can be concluded that contact angle measurements represent an efficient method to assess paper printing behavior, with the advantage of being faster than many measurements of printing quality parameters.

However, and regarding line and dot quality (image definition parameters), it was found that a total hydrophobic character may also be detrimental in certain parameters, emphasizing that there are competing variables that must be taken into account. In fact, paper surface treatment must be performed in such a way that some surface hydrophilic character is kept, allowing surface wetting.

\section{REFERENCES}

(1) Rutar, V.; Hladnik, A. Penetration tests and influence of paper sheet structure on its sorption ability. Presented at the COST Action E11 Workshop, Grenoble, 2000.

(2) Oliver, J.; Chen, J.; Tosto, F.; Silvy, J; Costa, P. Impact of paper surface structure on print quality. Presented at the COST E11 Meeting, Espoo, October 2001. 
(3) Brandão, E.; Colagem superficial: Experiência e reflexões sobre sua aplicação. Presented at the XVI Encontro Tecnicelpa, Covilhã; 1999.

(4) Keskitalo, I. The penetration of water-based inks into laboratory sheets made from bleached eucalipt kraft pulp. Master's Thesis, Luleå Tekniska Universitet, Sweden, 2000.

(5) Koskela, J P.; Hormi, O. E. O. Improving the printability of paper with long-chain quaternaries. Appita Journal. 2003, 56(4), 296-300.

(6) Pruszynski, P. Recent developments in papermaking chemicals, WWP Keynote lectures, 2003, 8290.

(7) Breda, J. P. M. D. Estudo do efeito da composição da mistura fibrosa na qualidade de impressão com jacto de tinta, Master's Thesis, Beira Interior University, Covilhã, Portugal, 2001.

(8) Hladnik, A. Ink-jet printing and image analysis, Technical Seminar, Beira Interior University, Covilhã, Portugal, 2003.

(9) Hamers, C., others. Curtain coating for graphic. Pulp \& Paper International. 2005, 47, 36-37.

(10) Forsström, U.; Fagerholm, K.; Saharenen. The role of base paper porosity in MSP coating. Paperi ja Puu-Paper and Timber. 2003, 85(8), 454-459.

(11) Donigian, D. W.; Ishley, J. N.; Wise, K. J. Coating pore structure and offset printed gloss. Tappi Journal. 1997, 80(5), 163-172.

(12) NIST Chemistry Webbook. http://webbook.nist.gov/chemistry/ (accessed October 2006).

(13) Allen, G; Bevington, J.C. Comprehensive Polymer Science - The Synthesis, Characterization, Reactions \& Applications of Polymers; Pergamon Press: Oxford, 1989, p. 707. 
(14) Stout, K.J.; Sullivan, P.J.; Dong, W.P.; Mainsah, E.; Luo, N.; Mathia, T.; Zahouani, H. Publication no. EUR 15178 EN of the Commission of the European Communities, Luxembourg, 1994.

(15) Bico, J.; Thiele, U.; Quéré, D. Wetting of textured surfaces. Colloids and Surfaces A: Physicochemical and Engineering Aspects. 2002, 206, 41-46.

(16) Lai, S. C. S. Mimiching nature: Physical basis and artificial synthesis of the Lótus-effect. Thesis, Leiden University, 2003.

(17) Swain, P.; Lipowsky, R. Contact angles on heterogeneous surfaces: a new look at Cassie's and Wenzel's laws. Cornell University Library (http://arxiv.org). 1998, 1-10.

(18) Wågberg, L.; Westerlind, C. Spreading of droplets of different liquids on specially structured papers. Nordic Pulp and Paper Research Journal. 2000, 15(5), 598-606.

(19) Lee, H.; Joyce, M. K.; fleming, P., D.; Cawthorne, J. E. Influence of silica and alumina oxide on coating structure and print quality of inkjet papers. TAPPI JOURNAL. 2005, 4(2), 11-16.

(20) Dataphysics. Surface chemistry - The Fundamentals of contact angle measurements; OCA 20 instructions manual; n.d..

(21) Tappi standard T558 om-97.

(22) Tappi standard T458 om-89.

(23) Moutinho, I., Figueiredo, M., Ferreira, P. Evaluting the surface energy of laboratory-made paper sheets by contact angle measurements. TAPPI JOURNAL. 2007, 6(6), 26-32.

(24) Papermaking Science and Technology - Book 13; Gullichsen J., Paulapuro Ed.; Fapet Oy: Helsinki, 1999; p. 33, 75-77. 
(25) Papermaking Science and Technology - Book 17; Gullichsen J., Paulapuro Ed.; Fapet Oy: Helsinki, 1999; p. 171.

(26) Shen, W.; Filonanko, Y.; Truong, Y.;Parker, I. H.; Brack, N.; Pigram, P.; Liesegang, J. Contact angle measurement and surface energetics of sized and unsized paper. Colloids and Surfaces A: Physicochemical and Engineering Aspects. 2000, 173, 117-126. 